\title{
Theoretical Comparative Study of Mirror Width on the Performance of Horizontal Receiver LFRSC
}

M. Babu ${ }^{1}$ and Dr. A. Valan Arasu ${ }^{2}$

\begin{abstract}
A Linear Fresnel reflector Solar concentrating (LFRSC) system consists of number of flat mirrors kept on a horizontal base at a certain tilted angles, which reflects the sun's rays into a central receiver held above them. In this paper, we have made a comparative study between two different LFRSC systems with tubular absorber. The first LFRSC system has reflector plates of same width and the second system has reflector plates of varying width. The objective of this paper is to find the optimum design parameters for each case and to find the best between the two the systems. By varying various design parameters like width of the reflector plates, shift between the plates, the height of the receiver tube from the reflector plane and diameter of the receiver tube, calculations were done. The solar flux is considered to be a constant of $0.6 \mathrm{~kW} / \mathrm{m}^{2}$ and the reflector plates are assumed to be made of glass $(\rho=0.98)$. Concentration ratio and concentrated flux are determined for each case and graphs are plotted for comparison. Results show that the LFRSC system with same width plates has better efficiency $(C . P=3.15 \mathrm{~kW}$ and C.R=103.3) than those with varying width plates, while considering optimum design parameters of height from reflector plane, width of the plates and diameter of the receiver tube as $1.5 \mathrm{~m}, 0.03 \mathrm{~m}$ and $0.015 \mathrm{~m}$ respectively for a certain range considered.
\end{abstract}

\section{INTRODUCTION}

\section{Dissertation Idea:}

With the decrease in fossil fuel supply and increase in population and global warming threats people are now looking for ways to harness non-conventional sources of energy. Considerable attention has been paid of late to develop linear Fresnel reflecting concentrators for thermal and photovoltaic conversion of the solar energy. Solar energy is a renewable energy which can be efficiently utilized, specially the concentrated solar power; the commercially available concentrated solar power technologies are solar tower, parabolic trough, dish-stirling engine and linear Fresnel solar system. Liner Fresnel solar system is currently low cost and widely spread technology for large scale solar thermal power.

Linear Fresnel Reflector (LFR) is a line-focusing system. A typical LFR uses modular, flat mirrors that track the sun to focus the sun's heat onto long, elevated tubular receiver (absorber) through which water flows. The concentrated sunlight boils the water in the tubes, generating hot water, saturated or superheated steam for use in power generation in steam Rankin cycle for instance or for process heat in industrial applications.

${ }^{1}$ Department of Mechanical Engineering, Kings College of Engineering, Thanjavur,Tamil Nadu, INDIA.

${ }^{2}$ Department of Mechanical Engineering, Kings College of Engineering, Thanjavur,Tamil Nadu, INDIA. 


\section{LITERATURE SURVEY:}

Concentration of solar energy is essential for effective conversion to other forms of energy (John.A.Duffie, and Beckman, 1980: Harry K.Charles, 1983). A LFRC system consists of number of flat mirrors kept on a horizontal base at a certain tilted angles, which reflects the sun's rays into a central receiver held above them. The mirrors are oriented in such a way that they form a linear image of sun on the receiver.(Choudhury \&Sehgal,1986).

Fresnel reflecting concentrator has several advantages, (i) it is useful for medium-temperature range $\left(100-250{ }^{\circ} \mathrm{C}\right)$ applications; (ii) it is fabricated with narrow flat mirrors and constituent materials for its fabrication as well as replacement are readily available in the market; (iii) the planar configuration and the air gap between the adjacent mirrors result in very small wind loading on the concentrator. Because of this, it can be mounted on rather simple cost-effective supporting structure.

The efficiency of the system depends upon various parameters like design, coatings applied, number of mirrors used, type of working fluid, mass flow rate of the working fluid, tracking system, etc., (Sharma et al,1983). This paper presents a theoretical analysis on two different models of linear Fresnel concentrating system. In one model, reflective mirror elements of equal width are used whereas in another model reflective mirror elements of varying width are considered for the reflector plates. The angular subtense of sun at any point on earth isconsidered to be 32' while designing the concentrators (Negi et al ). With glass as reflector plates, the concentrated ratio and concentrated power in each case are analyzed theoretically by varying diameter of the tube, width of the plates, shift between the plates and height from the reflector plane. The results of the theoretical analysis are presented and discussed in this paper.

\section{PROBLEM DEFINITION AND SCOPE}

\section{Problem Definition:}

The objective of this paper is to find the optimum design parameters for each case of and to find the best between the two systems. By varying various design parameters like width of the reflector plates, shift between the plates, the height of the receiver tube from the reflector plane and diameter of the receiver tube, calculations are to be done

\section{Scope:}

- Theoretical study of four LFRSC systems.

- Horizontal absorber with constant width reflectors.

- Horizontal absorber with varying width reflectors.

- Performance analysis of the four systems in terms of concentration ratio.

- Determination of the number of contributing reflector mirror strips in the considered collector aperture area.

- Determination of the width of reflectors using analytical technique.

\section{Objectives:}

- Design a Linear Fresnel Reflector Solar Concentrating System

- Optimize the design parameters of the System.

- Study of reflector Mirror width performance.

\section{SYSTEM DESIGN}

\section{Design of CLRFC Systems:}




\section{Assumptions and Design Parameters Considered:}

The following assumptions are considered for the analysis:

(i) The concentrator is perfectly tracked (Negi et al.) so as to follow the apparent movement of the sun

(ii) The reflector elements are specularly reflective.

(iii) solar radiation is constant $\left(=0.6 \mathrm{~kW} / \mathrm{m}^{2}\right)$ and is incident normally on the reflector plane

It is considered that there are $(2 \mathrm{~N}+1)$ reflector elements in both the systems, with $\mathrm{N}$ reflectors on each side of the central receiver which is kept symmetrically about and normal to the optical plane of the concentrating system. The reflectors are oriented so as to form an overlapping image of the sun on the receiver tube. The main design characteristics of the system are shift, location, tilt and width considering the mirror elements (Choudhry and Sehgal, 1986). The diameter of the receiver tube and height from the base also matters. By properly identifying the optimum values from these parameters, the efficiency of the system can be increased.

Two different models of LFRC system considered are (i) horizontal receiver tube with same width reflecting plates (ii) horizontal receiver system with varying width reflector plates. The design parameters for each case are analyzed theoretically with the above mentioned assumptions and the concentrated ratio and concentrated power are found out and compared for the optimum design conditions.

\section{Horizontal Receiver with Same Width Plates:}

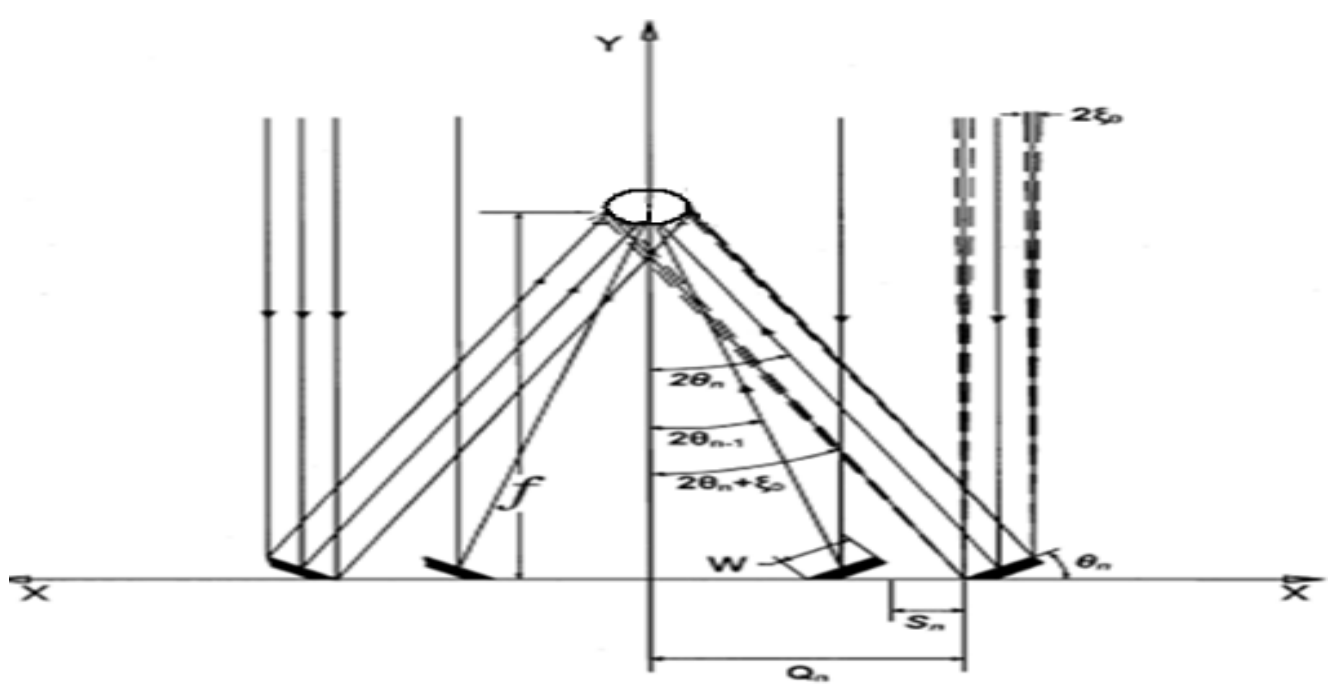

Figure 1: A linear Fresnel solar concentrating system employing reflector plates of same width.

Figure 1 describes a horizontal receiver system with central tubular receiver. Equal numbers of mirrored reflectors of same width (W) are kept on both sides of the receiver tube. Each of the plates is kept at a certain tilt angle calculated based on the location of the plate and diameter of the receiver such that the incident rays are focused onto the central receiver tube. The shift between each plate is determined from the tilt angle appropriately. The following are the equations used to obtain the tilt, shift and location (Manikumar \& Valan Arasu 2013)

$$
\begin{aligned}
& \theta_{\mathrm{n}}=1 / 2 *\left(\tan ^{-1}\left(\mathrm{Rn}+(\mathrm{d} / 2) \cos \theta_{\mathrm{n}-1}\right) /\left(\mathrm{h}-\mathrm{W} / 2 \cdot \sin \theta_{\mathrm{n}-1}\right)\right. \\
& \mathrm{S}_{\mathrm{n}}=\mathrm{W}^{*} \sin \theta_{\mathrm{n}-1} * \tan \left(2 \theta_{\mathrm{n}}+\mathrm{C}\right)
\end{aligned}
$$




$$
\mathrm{Q}_{\mathrm{n}}=\mathrm{Q}_{\mathrm{n}-1}+\mathrm{W} \cdot \cos \theta_{\mathrm{n}-1}+\mathrm{S}_{\mathrm{n}}
$$

where $\mathrm{W}$ is width of each mirror element, and $\epsilon$ is half of the angular subtense of the sun at any point on the earth (=16') (solarserver.com).

With $\theta_{0}=0, \mathrm{~S}_{1}=0, \mathrm{Q}_{0}=-\mathrm{W} / 2, \mathrm{Q}_{1}=\mathrm{W} / 2$ as initial values for the iteration and $\mathrm{n}=1,2, \ldots, \mathrm{m}$, where, ' $\mathrm{m}$ ' is the total number of mirror elements placed on each half of the reflector. Here $\mathrm{m}$ is chosen as 40 . Concentration ratio (CR) of the Fresnel collector was obtained by summing up the concentration contribution of the $n^{\text {th }}$ mirror element. Contribution of concentration of $n^{\text {th }}$ mirror element $\left(\mathrm{CI}_{n}\right)$ to the local concentration ratio distribution on absorber plane was calculated as [3]

$$
\begin{aligned}
& \mathrm{P}_{\mathrm{n}}=0.6 * 0.7 * \mathrm{~W}^{*} \cos \left(\theta_{\mathrm{n}}\right) * \mathrm{~L} \\
& \mathrm{P}_{\mathrm{c}}=0.6^{*} 0.7 *(\mathrm{~W}-\mathrm{d}) * \mathrm{~L} \\
& \mathrm{CP}=2 \sum_{n=1}^{N} P_{n}+\mathrm{P}_{\mathrm{c}}(6) \\
& \mathrm{CR}=2 \sum_{n=1}^{m} C I_{n} \\
& \mathrm{CI}_{\mathrm{n}}=\left(\mathrm{W}^{*} \cos \left(\theta_{\mathrm{n}}\right)\right) / \mathrm{Gn} \\
& \mathrm{I}_{\mathrm{n}}=\mathrm{h}-\left(\mathrm{W}^{*} \sin \left(\theta_{\mathrm{n}}\right) * \sin (0.0046542) / \cos \left(2 \theta_{\mathrm{n}}\right)\right) / \cos \left(\left(2 \theta_{\mathrm{n}}\right)-0.0046542\right) \\
& \mathrm{J}_{\mathrm{n}}=\left(\mathrm{W}^{*} \cos \left(\theta_{\mathrm{n}}\right) *\left(1 / \cos \left(2 * \theta_{\mathrm{n}}\right)\right)\right) \\
& \left.\mathrm{K}_{\mathrm{n}}=\mathrm{h} *\left(1 / \cos \left(2 * \theta_{\mathrm{n}}\right)\right) * \sin (0.0046542)\right) / \cos \left(\left(2 * \theta_{\mathrm{n}}\right)+0.0046542\right.
\end{aligned}
$$

The concentrated ratio and the power were obtained from the above equations. The diameter range is assumed to be from $0.015 \mathrm{~m}$ to $0.04 \mathrm{~m}$ and the focal height range is considered from $0.5 \mathrm{~m}$ to $2.0 \mathrm{~m}$ and the width range from $0.02 \mathrm{~m}$ to $0.035 \mathrm{~m}$.

From the Table 1 it can be found that the concentrated power is 3.22 obtained for $2 \mathrm{~m}$ focal height is greater than the concentrated power obtained for $1.5 \mathrm{~m}$ but the Concentrated Ratio remains same hence $1.5 \mathrm{~m}$ focal height is selected, the best values were obtained for height of $1.5 \mathrm{~m}$, width of plates as $0.03 \mathrm{~m}$ and diameter of the plate as $0.02 \mathrm{~m}$. The shift between each plate is considered based on the tilt angle as defined in (2).

\section{Horizontal Receiver System with Different Width Plates:}

Figure 2 shows horizontal receiver system with varying width plates. By reducing the width of the reflector plates at the rear ends of the concentrator, the angular dispersion which affects the optical efficiency of the concentrator could be controlled.

Considering the case of a concentrator with $(2 \mathrm{~N}+1)$ mirror strips, such that it has a central zone of $(2 \mathrm{~K}+1)$ strips of width, $\mathrm{W}$, and spacing $\mathrm{S}$ and another zone of extra-axial mirrors beyond the kth mirror of width $\mathrm{W} 1(<\mathrm{W})$ and shift $\mathrm{S} 1(>\mathrm{S})$. 


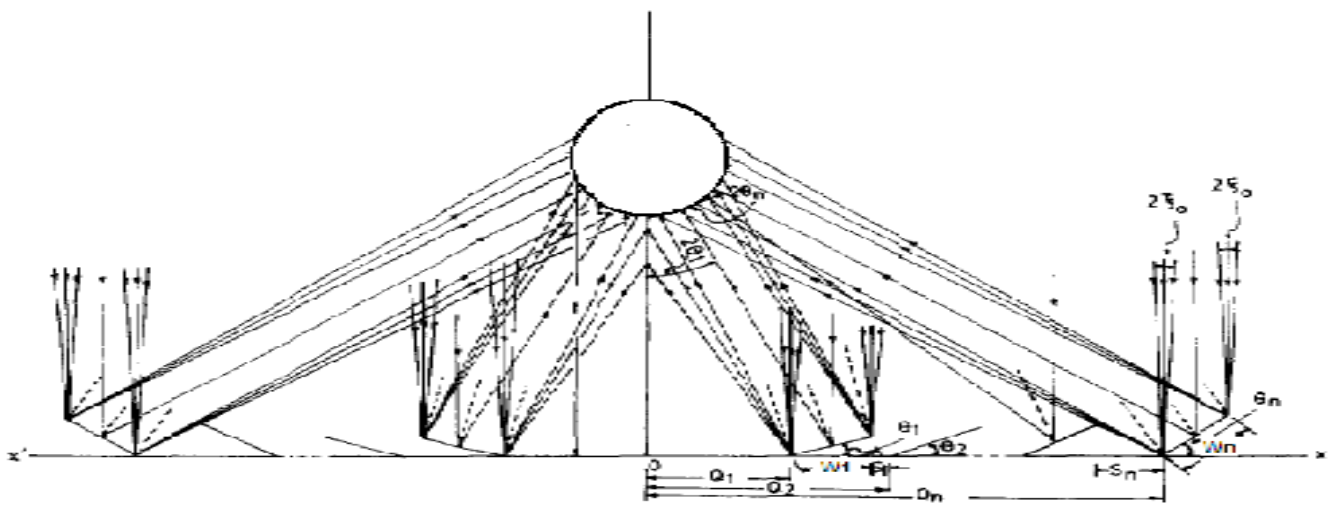

Figure 2: Horizontal receiver system with varying width plates.

The location $\mathrm{R}_{\mathrm{n}}$ for the mirror strips from first to $\mathrm{k}^{\text {th }}$ can be expressed as

$$
\mathrm{R}_{\mathrm{n}}=\mathrm{n}(\mathrm{W}+\mathrm{S})-(\mathrm{W} / 2)
$$

where $\mathrm{n}$ takes values from 1 to $\mathrm{k}$, and $\mathrm{R}_{\mathrm{n}}$, for the $(\mathrm{k}+1)^{\text {th }}$ upto the outermost $\left(\mathrm{n}^{\text {th }}\right)$ mirror element, is expressed as:

$$
\mathrm{R}_{\mathrm{n}}=\mathrm{R}_{\mathrm{k}}+(\mathrm{n}-\mathrm{k})\left(\mathrm{W}_{1}+\mathrm{S}_{1}\right)
$$

The angle of tilt of the plates are calculated using:

$$
\theta_{\mathrm{n}}=1 / 2 *\left(\tan ^{-1}\left(\mathrm{R}_{\mathrm{n}}+(\mathrm{d} / 2) / \mathrm{h}\right)\right)
$$

Power from the nth plate and the central plate in $\mathrm{kW}$ are given below respectively:

$$
\begin{aligned}
& \mathrm{P}_{\mathrm{n}}=0.6 * 0.7 * \mathrm{~W}^{*} \cos \left(\theta_{\mathrm{n}}\right) * \mathrm{~L} \\
& \mathrm{P}_{\mathrm{c}}=0.6 * 0.7 *(\mathrm{~W}-\mathrm{d}) * \mathrm{~L}
\end{aligned}
$$

Contribution of concentration ratio of each of the reflector plates to the local concentration ratio distribution on the absorber plane is given by the following equations: [3] 
Table 1:optimized values the focal height, width and diameter for maximum CP \& CR

\begin{tabular}{|c|c|c|c|c|}
\hline Height (m) & Width (m) & Diameter $(\mathbf{m})$ & C.P $(\mathbf{k W})$ & $\mathbf{C . R}$ \\
\hline 0.50 & 0.02 & 0.02 & 1.79 & 68.75 \\
\hline 1.00 & 0.02 & 0.02 & 2.05 & 68.75 \\
\hline 1.50 & 0.02 & 0.02 & 2.14 & 68.75 \\
\hline 2.00 & 0.02 & 0.02 & 2.16 & 68.75 \\
\hline 0.50 & 0.03 & 0.02 & 1.19 & 85.94 \\
\hline 1.00 & 0.03 & 0.02 & 2.50 & 85.94 \\
\hline 1.50 & 0.03 & 0.02 & 2.65 & 85.94 \\
\hline 2.00 & 0.03 & 0.02 & 2.70 & 85.94 \\
\hline 0.50 & 0.03 & 0.02 & 1.74 & 103.13 \\
\hline 1.00 & 0.03 & 0.02 & 2.94 & 103.13 \\
\hline $\mathbf{1 . 5 0}$ & $\mathbf{0 . 0 3}$ & $\mathbf{0 . 0 2}$ & $\mathbf{3 . 1 6}$ & $\mathbf{1 0 3 . 1 3}$ \\
\hline 2.00 & 0.03 & 0.02 & 3.22 & 103.13 \\
\hline 0.50 & 0.02 & 0.02 & 1.80 & 51.57 \\
\hline 1.00 & 0.02 & 0.02 & 2.04 & 51.57 \\
\hline 1.50 & 0.02 & 0.02 & 2.13 & 51.57 \\
\hline 2.00 & 0.02 & 0.02 & 2.16 & 51.57 \\
\hline 0.50 & 0.03 & 0.02 & 1.19 & 64.46 \\
\hline 1.00 & 0.03 & 0.02 & 2.50 & 64.46 \\
\hline 1.50 & 0.03 & 0.02 & 2.65 & 64.46 \\
\hline 2.00 & 0.03 & 0.02 & 2.69 & 64.46 \\
\hline 0.50 & 0.03 & 0.02 & 1.73 & 77.35 \\
\hline 1.00 & 0.03 & 0.02 & 2.93 & 77.35 \\
\hline 1.50 & 0.03 & 0.02 & 3.16 & 77.35 \\
\hline 2.00 & 0.03 & 0.02 & 3.22 & 77.35 \\
\hline 0.50 & 0.02 & 0.03 & 1.79 & 41.25 \\
\hline 1.00 & 0.02 & 0.03 & 2.04 & 41.25 \\
\hline 1.50 & 0.02 & 0.03 & 2.13 & 41.25 \\
\hline 2.00 & 0.02 & 0.03 & 2.16 & 41.25 \\
\hline & & & & \\
\hline
\end{tabular}

$\mathrm{I}_{\mathrm{n}}=\mathrm{h}-\left(\mathrm{W}^{*} \sin \left(\theta_{\mathrm{n}}\right) * \sin (0.0046542) / \cos \left(2 \theta_{\mathrm{n}}\right)\right) / \cos \left(\left(2 \theta_{\mathrm{n}}\right)-0.0046542\right)$

$\mathrm{J}_{\mathrm{n}}=\left(\mathrm{W} * \cos \left(\theta_{\mathrm{n}}\right) *\left(1 / \cos \left(2 * \theta_{\mathrm{n}}\right)\right)\right)$

$$
\mathrm{K}_{\mathrm{n}}=\left(\mathrm{h} *\left(1 / \cos \left(2 * \theta_{\mathrm{n}}\right)\right) * \sin (0.0046542)\right) / \cos \left(\left(2 * \theta_{\mathrm{n}}\right)+0.0046542\right)
$$

$\mathrm{G}_{\mathrm{n}}=\mathrm{I}_{\mathrm{n}}+\mathrm{J}_{\mathrm{n}}+\mathrm{K}_{\mathrm{n}}$

$$
\mathrm{CI}_{\mathrm{n}}=\left(\mathrm{W}^{*} \cos \left(\theta_{\mathrm{n}}\right)\right) / \mathrm{G}_{\mathrm{n}}
$$

$\mathrm{CP}=2 \sum_{n=1}^{N} P_{n}+\mathrm{P}_{\mathrm{c}}$

$\mathrm{CR}=2 \sum_{n=1}^{m} C I_{n}$

With the above given equations, the diameter is assumed from a range of $0.015 \mathrm{~m}$ to $0.04 \mathrm{~m}$ and the height is considered for a range of $0.5 \mathrm{~m}$ to $2.0 \mathrm{~m}$ and the width up to $\mathrm{k}^{\text {th }}$ mirror is considered from $0.05 \mathrm{~m}$ to $0.08 \mathrm{~m}$ and the width from the $\mathrm{k}^{\text {th }}$ to $\mathrm{n}^{\text {th }}$ plate is considered to be a range of $0.02 \mathrm{~m}$ to $0.06 \mathrm{~m}$. And the shift is considered from $0.002 \mathrm{~m}$ to $0.01 \mathrm{~m}$ till $\mathrm{k}_{\text {th }}$ plate and $0.005 \mathrm{~m}$ to $0.014 \mathrm{~m}$ for $\mathrm{k}^{\text {th }}$ to $\mathrm{n}^{\text {th }}$ plates. The concentrated ratio and concentrated power are obtained for the above cases and it is seen that the best values are obtained at $1.5 \mathrm{~m}$ height, inner width $0.07 \mathrm{~m}$, outer width $0.06 \mathrm{~m}$, diameter $0.02 \mathrm{~m}$, inner shift $0.002 \mathrm{~m}$ and outer shift $0.005 \mathrm{~m}$ with concentrated power and concentrated ratio as $2.044 \mathrm{~kW}$ and 84.99. 


\section{RESULTS AND DISCUSSION}

From the above tabulations table 1 the values for the same width LFR system are optimized with the focal height of $1.5 \mathrm{~m}$, width $0.03 \mathrm{~m}$ and diameter $.02 \mathrm{~m}$ with the same focal height $1.5 \mathrm{~m}$ the width of the reflectors are changed from the range of $0.02 \mathrm{~m}$ to $0.06 \mathrm{~m}$. The optimized values obtained at $1.5 \mathrm{~m}$ height, inner width $0.07 \mathrm{~m}$, outer width $0.06 \mathrm{~m}$, diameter $0.02 \mathrm{~m}$, inner shift $0.002 \mathrm{~m}$ and outer shift $0.005 \mathrm{~m}$. In the linear system the height is considered within $2 \mathrm{~m}$ as assumed value and since $1.5 \mathrm{~m}$ has a closer value of concentrated power to $2 \mathrm{~m}$, height is selected $1.5 \mathrm{~m}$ in which the maximum CR is obtained. The concentrated power decreases with increase in diameter of the receiver tube which is shown in fig. 3 thus the diameter is optimized to $0.02 \mathrm{~m}$. On the other hand, as the width increases the concentrated power increases as shown in figure 4 thus comparison was made with different width of plates and found to be same width plates give better output than varying width plates the width of the plate for same width LFR system is optimized $0.03 \mathrm{~m}$ and the performance is analyzed.

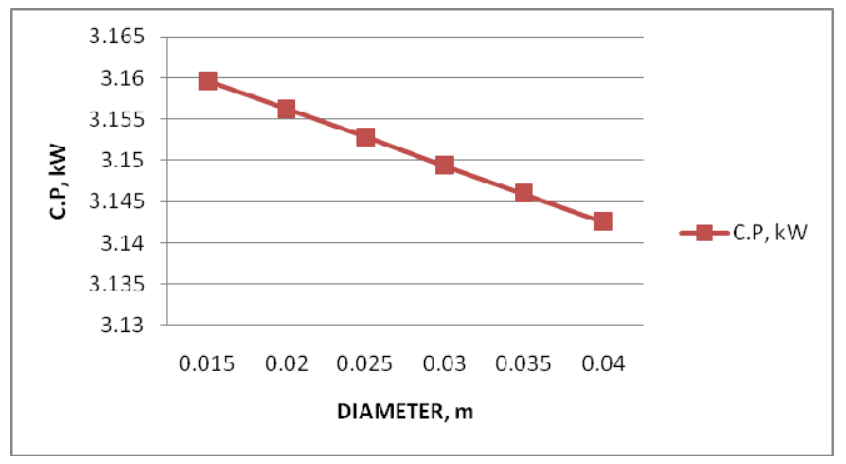

Figure 3: Variation of C.P w.r.t diameter of the absorber (Case 1)

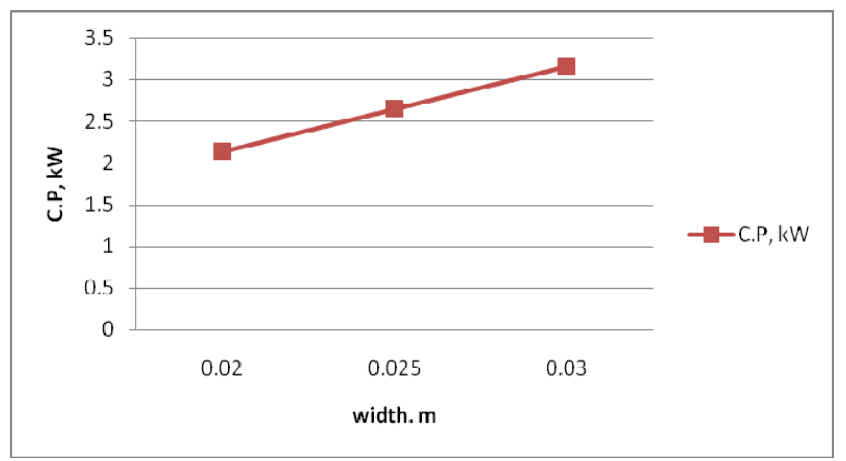

Figure 4: Variation of C.P w.r.t width of the plates (Case 2) 
Table 2: Optimized values for varying width of reflectors

\begin{tabular}{|c|c|c|c|c|c|c|c|}
\hline $\begin{array}{c}\text { Height } \\
(\mathrm{m})\end{array}$ & $\begin{array}{c}\text { Width1 } \\
(\mathrm{m})\end{array}$ & $\begin{array}{c}\text { Width2 } \\
(\mathrm{m})\end{array}$ & $\begin{array}{c}\text { Diameter } \\
(\mathrm{m})\end{array}$ & $\begin{array}{c}\text { Shift1 } \\
(\mathrm{m})\end{array}$ & $\begin{array}{c}\text { Shift2 } \\
(\mathrm{m})\end{array}$ & $\begin{array}{c}\text { C.P } \\
(\mathrm{kW})\end{array}$ & C.R \\
\hline 0.50 & 0.07 & 0.06 & 0.02 & 0.00 & 0.01 & 1.84 & 84.99 \\
\hline 0.50 & 0.07 & 0.06 & 0.02 & 0.01 & 0.01 & 1.84 & 84.99 \\
\hline 1.00 & 0.07 & 0.06 & 0.02 & 0.00 & 0.01 & 1.97 & 84.99 \\
\hline 1.00 & 0.07 & 0.06 & 0.02 & 0.01 & 0.01 & 1.96 & 84.99 \\
\hline 1.50 & 0.07 & 0.06 & 0.02 & 0.00 & 0.01 & 2.04 & 84.99 \\
\hline 1.50 & 0.07 & 0.06 & 0.02 & 0.01 & 0.01 & 2.04 & 84.99 \\
\hline 2.00 & 0.07 & 0.06 & 0.02 & 0.00 & 0.01 & 2.04 & 84.99 \\
\hline 2.00 & 0.07 & 0.06 & 0.02 & 0.01 & 0.01 & 2.04 & 84.99 \\
\hline
\end{tabular}

Table 3: Final output values for both same and varying width reflectors

\begin{tabular}{|l|c|c|c|c|c|}
\hline \multicolumn{1}{|c|}{ System } & $\begin{array}{c}\text { Height } \\
(\mathrm{m})\end{array}$ & $\begin{array}{c}\text { Diameter } \\
(\mathrm{m})\end{array}$ & $\begin{array}{c}\text { Width } \\
(\mathrm{m})\end{array}$ & $\begin{array}{c}\mathrm{CP} \\
(\mathrm{kW})\end{array}$ & CR \\
\hline $\begin{array}{l}\text { Horizontal } \\
\text { receiver with } \\
\text { same width } \\
\text { reflectors }\end{array}$ & 1.50 & 0.02 & 0.03 & 3.16 & 103.13 \\
\hline $\begin{array}{l}\text { Horizontal } \\
\text { receiver with } \\
\text { varying width } \\
\text { reflectors }\end{array}$ & 1.50 & 0.02 & 0.06 & 2.04 & 84.99 \\
\cline { 2 - 5 } & & 0.02 & & \\
\hline
\end{tabular}

From the above tabulations Table 1, Table 2 and Table 3 it can be seen that the horizontal receiver system with same width plates has better concentrated power and concentration ratio than the varying width system. The comparison between the two systems is shown in table 3.

\section{CONCLUSIONS AND FUTURE SCOPE}

The theoretical study on the two LRFC systems is done using a software called Dev C++ to execute the $\mathrm{C}$ language programming written to accomplish the required calculations. With 40 numbers of reflectors considered in each case and by varying parameters like width of the plates, diameter of the receiver, height of the receiver and shift between the plates, concentrated power and concentrated ratio are found out. From the results shown it is seen that the LRFC system with reflector plates of equal width has better concentrated ratio and concentrated power than the LFRC with varying width plates for the optimum design values considered. The designed analytical values can be further taken for optimization techniques like Genetic Algorithm (GA) or Particle Swarm Optimization (PSO). Then in future it can be taken for experimental analysis to validate the system design.

\section{Nomenclature}

\begin{tabular}{|l|l|}
\hline Symbol & Description \\
\hline$\theta$ & Tilt angle of plates in degrees \\
\hline
\end{tabular}




\begin{tabular}{|l|l|}
\hline $\mathrm{R}$ & Range from the centre in $\mathrm{m}$ \\
\hline $\mathrm{P}$ & Power reflected from plates in $\mathrm{kW}$ \\
\hline $\mathrm{n}, \mathrm{k}$ & No.of plates \\
\hline $\mathrm{W}$ & Width of the reflector plates in $\mathrm{m}$ \\
\hline $\mathrm{d}$ & Diameter of the absorber tube in $\mathrm{m}$ \\
\hline $\mathrm{S}$ & Shift between the plates in $\mathrm{m}$ \\
\hline $\mathrm{L}$ & Length of the absorber tube in $\mathrm{m}$ \\
\hline $\mathrm{h}$ & $\begin{array}{l}\text { Height of the absorber tube from the base } \\
\text { in } \mathrm{m}\end{array}$ \\
\hline $\mathrm{CP}$ & Total Concentrated Power in $\mathrm{KW}$ \\
\hline $\mathrm{CR}$ & Concentrated Ratio \\
\hline $\mathrm{CI}$ & Concentrated Power from a plate in $\mathrm{kW}$ \\
\hline
\end{tabular}

\section{REFERENCES}

[1] Panna Lal Singh, R.M. Sarviya, J.L. Bhagoria,“ Thermal performance of linear Fresnel reflecting solar concentrator with trapezoidal cavity absorbers" Vol 87, Issue 2, pp 541-550, 2010.

[2] B.S.Negi, T.C.Kandpal and S.S.Mathur, 'Designs and performance characteristics of a linear Fresnel concentrator with a flat vertical absorber" Sol.Wind Technol. 7 -379-392(1990).

[3] Sharma, M.S., Sehgal, A.K., Kandpal, T.C., Mathur, S.S., Geometrical optical design and performance studies of a linear Fresnel reflector" energy acontinuing bibliogsaphy with index isst ts 33 (NASA Scientific and Technical) (1982).

[4] Choudhury, C. and Sehgal, H.K . "A Fresnel strip reflector concentrator for tubular solar-energy collectors" Applied Energy, vol. 23, issue 2, pages 143-154,(1986).

[5] John.A.Duffie and Beckman W.A., "Solar Engineering of Thermal Processes". John Wiley, New York (1980).

[6] Manikumar R., Valan Arasu Design and theoretical performance analysis of linear Fresnel reflector solar concentrator with a tubular absorber. International Journal of Renewable Energy Technology (IJRET), Vol. 3, No. 3, (2012)

[7] D.R.Mills, G.L.Morrison, and P.Le Lièvre,School of Physics,University of Sydney,Sydney, AUSTRALIA Project Proposal for a Compact Linear Fresnel Reflector Solar Thermal Plant in the Hunter Valley(2006)

[8] D.R. Mills Compact Linear Fresnel Reflector solar thermal power plants *School of Physics, University of Sydney, Sydney 2006, Australia,School of Mechanical and Manufacturing Engineering, University of New South Wales, New South Wales 2052, Australia Received 25 November 1998; revised version accepted 30 August 1999 (2000)

[9] B Negi, S Mathur, T Kandpal Optical and thermal performance evaluation of a linear fresnel reflector solar concentrator. Solar Wind Technology. (1989)

[10]John D Pye, Graham L Morrison, David R Mills, Paul Le Lièvre, Steam-circuit Model for the Compact Linear Fresnel Reflector Prototype Solar 2004: Life, the Universe and Renewables, Solar Heat and Power Pty Ltd, Level 25 Chifley Tower, 2 Chifley Sq, Sydney NSW 2000

[11]Franois Veynandt, Jrmie De La Torre, Jean Jacques Bezian, Abhik Ghatuary. Design optimization of a solar power plant based on linear fresnel reflector. 16th SolarPACES Conference, Perpignan, France September (2010)

[12] Cesare Silvi in SolarPACES Conference. The Pioneering Work on Linear Fresnel Reflector Concentrators in Italy SolarPACES Conference (2009)

[13] Dr. Andreas Häberle, Linear Fresnel Collectors,Springer Solar Energy, pp 72-78 (2013)

[14] www.solarserver.com/knowledge/basic-knowledge/solar-collectors.html 